\title{
Introduction of the Indian Society for Mass Spectrometry (ISMAS) (http:// www.ismas.org)
}

\author{
Suresh K. Aggarwal \\ Indian Society for Mass Spectrometry, c/o Fuel Chemistry Division Bhabha Atomic Research Centre, Mumbai 400085 , \\ India
}

Received 7 March, 2012, Accepted 7 March 2012

First published on the web March 15, 2011; DOI: 10.5478/MSL.2012.3.1.001

Key words: Indian Society for Mass Spectrometry, Mass Spectrometry

The Indian Society for Mass Spectrometry (ISMAS) was founded on March 21, 1978 at a meeting of the mass spectrometrists from all over India at Bhabha Atomic Research Centre (BARC), Bombay during the First National Seminar on Mass Spectrometry. The Society was formed with the objectives of promoting and popularizing mass spectrometry and its applications in Research, Industry and other areas of Science. After 34 years, ISMAS now has more than 720 Life-Members and a few Corporate Members. The ISMAS members are from Research Institutes, Universities, Industries and Hospitals from all over India. The LifeMembers include Mass Spectrometrists from overseas and these are Non-Resident Indians and Mass Spectrometrists from Austria, Belgium, Germany, Israel, Italy, Japan, Singapore, UK, USA etc.

The activities of ISMAS are looked after by the President, the Secretary and the Executive Committee elected triennially by the ISMAS members. The previous Presidents and Secretaries were:

1. (1978-1985) Prof. V.B. Bhanot and Dr. C.K. Mathews

2. (1986-1991) Dr. C.K. Mathews and Dr. H.C. Jain

3. (1992-1994) Prof. E.S.R. Gopal and Dr. S.K. Aggarwal

4. (1995-1997) Dr. H.C. Jain and Dr. S.K. Aggarwal

5. (1998-2000) Prof. K. Gopalan and Shri V. K. Handu

6. (2001-2003) Dr S.K. Aggarwal and Dr P.M. Shah

7. (2004-2006) Dr S.K. Aggarwal and Sh. P.G. Jaison

8. (2007-2009) Dr. H.C. Jain and Sh. P.G. Jaison

Presently, Prof. Aggarwal S. K. is the President and Dr.(Ms.) D. Alamelu is the Secretary (2010-2012).

\section{ISMAS Triennial International Conference on Mass Spectrometry}

ISMAS International Conference on Mass Spectrometry

*Reprint requests to Dr. Suresh K. Aggawal, President of ISMAS E-mail: skaggr2002@rediffmail.com is held triennially. This provides a forum to research scholars, university faculty and research scientists from Research Institutes, Universities, Industries, Hospitals and other organizations to discuss their experiences and new developments in Mass Spectrometry. The Conference is organized by ISMAS and co-sponsored by a number of Departments of Government of India, other scientific organizations and Industries. These triennial Conferences on Mass Spectrometry have acquired International recognition in view of the participation of distinguished Mass Spectrometrists who are invited from different reputed Mass Spectrometric laboratories of the world. In view of the reputation of the ISMAS Conference, young Mass Spectrometrists working abroad also participate by sending their contributed papers. The contributed papers and the invited talks are published in the form of a bound Volume, prior to the beginning of the Conference.

Till date, Eleven Conferences have been organized.

1. March 20 to 22, 1978, Seminar on Mass Spectrometry -"Applications and Current Trends", BARC, Bombay.

2. December 21 to 23, 1981, National Symposium on Mass Spectrometry - "Progress in Research, Applications and Instrumentation", BARC, Bombay.

3. September 22 to 24, 1985, Third National Symposium on Mass Spectrometry, RRL, Hyderabad.

4. January 4 to 6,1988 , Fourth National Symposium on Mass Spectrometry, IISc, Bangalore.

5. January 7 to 9, 1991, Fifth National Symposium on Mass Spectrometry, PRL, Ahmadabad.

6. October 11 to 13, 1993, Sixth National Symposium on Mass Spectrometry, IIP, Dehradun.

7. November 26 to 28,1996 , Seventh National Symposium on Mass Spectrometry, DRDE, Gwalior.

8. December 7 to 9, 1999, Eighth ISMAS Symposium on Mass Spectrometry, IICT, Hyderabad.

9. January 27 to 31, 2003, ISMAS Silver Jubilee Symposium on Mass Spectrometry, [ISMAS-SJS-2003], 
NIO, Goa.

10. January 28 to February 1,2006 , Tenth ISMAS Triennial International Symposium on Mass Spectrometry, Tea County Resort, Munnar.

11. November 24 to 28, 2009, Eleventh ISMAS Triennial International Symposium on Mass Spectrometry, Ramoji Film City, Hyderabad.

\section{ISMAS Symposium cum Workshop on Mass Spectrometry}

ISMAS organizes Workshops on Mass Spectrometry at Research Institutes and Universities in different parts of India. These Workshops are aimed at introducing the subject of Mass Spectrometry to novices, updating the Mass Spectrometrists with the latest developments in the field, exposing the participants to innumerable applications of Mass Spectrometry and providing a common forum for discussing the day-to-day problems when working with a Mass Spectrometer. The programme of these Workshops consists of Tutorials, Panel Discussions, Research Scholar Presentations, Poster Presentations and Invited Lectures. The lectures include fundamentals of Mass Spectrometry, qualitative and quantitative aspects and data interpretation, maintenance of Mass Spectrometers, selection of a mass spectrometer, applications in various branches of science as well as recent advances in Mass Spectrometry. The lectures are supplemented by (i) Open-forum discussions on the experiences gained by the Resource Persons (faculty) as well as by the participants in running and maintaining the mass spectrometers and (ii) Visits to local laboratories equipped with mass spectrometers. During Workshop cum Symposium, Research Scholars are provided with an opportunity to make oral presentations of their research work. Cash Awards and Certificates of Merit are given to the best presentations. ISMAS Workshop has been renamed as 'ISMAS Symposium cum Workshop Seminar on Mass Spectrometry' with effect from April 2005.

Till date, 14 Workshops have been organized.

1. March 3 to 12, 1986, Workshop on "Maintenance of Mass Spectrometers", BARC, Bombay.

2. February 23 to 28, 1987, Winter School / Workshop on Mass Spectrometry, at Regional Sophisticated Instrumentation Center (RSIC), IIT, Madras.

3. February 20 to 24, 1989, Workshop on "Applications of Mass Spectrometry to Organic Chemistry and Biosciences", at DRDE, Gwalior.

4. March 1 to 5, 1993, Fourth National Workshop on Mass Spectrometry, at CDRI, Lucknow.

5. April 19 to 26, 1994, Fifth National Workshop on Mass Spectrometry at Regional Sophisticated Instrumentation Center (RSIC), Panjab University, Chandigarh.

6. February 28 to March 3, 1995, Sixth National Workshop on "Industrial and Environmental Applications of Mass
Spectrometry", at IGCAR, Kalpakkam.

7. August 21 to 25, 1995, Seventh National Workshop on "Advances in Mass Spectrometry: Instrumentation and Applications", at RRL, Thiruvananthapuram.

8. August 4 to 9, 1997, Eighth ISMAS Workshop on "Modern Trends in Mass Spectrometry", at BARC, Mumbai.

9. December 12 to 16,2000 , Ninth ISMAS Workshop on "Mass Spectrometry in the New Millennium: Instrumentation and Applications", at National Institute of Oceanography, Dona Paula, Goa.

10. February 25 to March 1, 2002, Tenth ISMAS Workshop (10th ISMAS-WS-2002) on "Advance in Mass Spectrometry" at Toshali Sands, Puri, in association with Institute of Physics, Bhubaneswar.

11. October 7 to 12, 2004, Eleventh ISMAS Workshop (11th ISMAS-WS 2004) on Mass Spectrometry at Toshali Royal View Resort, Shilon Bagh, Shimla in association with Niper, Mohali.

12. March 25-30, 2007, Twelveth ISMAS Workshop (12th ISMAS-WS 2007) on Mass Spectrometry at Cidadede-Goa, Dona Paula, Goa.

13. January 27 to 31,2008 , Thirteenth ISMAS Symposium cum Workshop (13th ISMAS-WS 2008) on Mass Spectrometry at BARC, Mumbai.

14. November 7-11, 2011, Fourteenth ISMAS Symposium cum Workshop (14 ${ }^{\text {th }}$ ISMAS-WS 2011) on Mass Spectrometry at Tea County, Munnar, Kerala

\section{ISMAS Discussion Meet on Mass Spectrometry}

ISMAS organizes Discussion Meets on specific applications of mass spectrometry at research institutes and universities in different parts of India. The Discussion Meet is aimed to discuss applications of mass spectrometry in focused area of research and updating the practitioners with the latest developments in the specific field of interest. The meet also provides a forum for discussing the day-to-day problems encountered in a selected area and find possible solutions. The following event was organized in association with Inter-University Accelerator Centre, New Delhi:

April 14-15, 2011, ISMAS International Discussion Meet on "Elemental Mass Spectrometry in Health and Environmental Sciences" (ISMAS-DM-HEAL-2011) at Clarion Collection Hotel, New Delhi.

\section{ISMAS Bulletin}

ISMAS brings out Special Souvenir cum Bulletins to inform its members of the activities. The bulletin also acts as a vehicle for informative articles on various topics in mass spectrometry. The regular publication of these ISMAS bulletins has been stopped due to austerity measures and existence of ISMAS web-site. The Special ISMAS Bulletin cum Souvenirs are brought out at the time of Symposium/ 


\section{Workshop/Conference.}

\section{Directory of Mass Spectrometers in India}

A Directory of Mass Spectrometers in India was first published in 1985 based upon the information received for the questionnaire sent to all the working groups and Indian Companies who are vendors of Mass Spectrometers. This Directory was finally updated in 2003. The Directory contains useful information about the types of mass spectrometers available in various laboratories in India, the year of purchase and the various applications along with the names of scientists engaged in the particular application.

\section{ISMAS Awards}

\section{Life-time achievement award}

ISMAS has instituted Life-Time Achievement Award for recognizing the outstanding contributions made by prominent mass spectrometrists, in each Symposium cum Workshop. The award carries a gold medal, a citation and a cash prize of Rs. 50,000/-.

\section{Eminent mass spectrometrist award}

ISMAS has instituted awards to recognize "Eminent Mass Spectrometrists" at each Triennial Symposium since 1991. Three awards are given at each triennial event. The award carries a medal, a citation and a cash prize of Rs. 25,000/-. The awards have been conferred upon:

1. Prof. K. Gopalan, NGRI, Hyderabad; Dr. H.C. Jain, BARC, Bombay and Dr. C.K. Mathews, IGCAR, Kalpakkam during 5th NSMS (1991).

2. Prof. V.B. Bhanot, Panjab University, Chandigarh; Shri B.S. Prahallada Rao; BARC, Bombay and Dr. M. Vairamani, IICT, Hyderabad during 6th NSMS (1993).

3. Dr. S.K. Aggarwal, BARC, Mumbai; Prof. D. Mathur, TIFR, Mumbai and Prof. D.V. Ramana, IIT, Chennai during 7th NSMS (1996).
4. Dr. K.P. Madhusudanan, CDRI, Lucknow and Dr. T.R. Venkatesan, PRL, Ahmadabad during 8th ISMAS Symposium (1999).

5. Prof. P.Chakraborty, SINP, Kolkata; Dr S.K.Raza, DRDE, Gwalior and Dr. R.Srinivas, IICT, Hyderabad during ISMAS Silver Jubilee Symposium (2003).

6 .Dr. V. Balaram, NGRI, Hyderabad; Sh. V. K. Handu, BARC, Mumbai and Prof. S.V.S. Murty, PRL, Ahmadabad during $10^{\text {th }}$ ISMAS Triennial International Symposium (2006).

7. Prof. A.K. Chakraborti, NIPER, Mohali, Dr B.R. Chakraborty, NPL, Delhi and Dr. R.K. Vatsa, BARC, Mumbai during $11^{\text {th }}$ ISMAS Triennial International Symposium (2009).

\section{Young scientist award}

ISMAS Young Scientist Award is instituted in recognition of the work carried out by a person of age below 35 years for the excellent work carried out in India. This award would consist a medal, citation and cash prize of Rs. 10,000/-.

\section{Research scholar award}

An award has been instituted for the Best Research Scholar presentation in every Workshop/Triennial Symposium organized by ISMAS. The winner is provided free registration, lodging and boarding for attending the next Symposium/Workshop.

\section{Other Activities}

ISMAS is also a member of International Mass Spectrometry Society (IMSS). This helps in providing information about ISMAS activities to all members of IMSS. ISMAS has its own website (www.ismas.org) which includes detailed information, news and upcoming events. ISMAS also considers providing partial support to its members to participate in the International Mass Spectrometry Conferences held outside India. 